\title{
Elevation Accuracy Assessment of a DSM and DTM Generated for an Urban Area from the ALTM 2025 Airborne Laser Scanning Sensor
}

\author{
Fernando Leonardi \\ Executive Director \\ Geopixel Geotechnologies Consulting \& Service Ltda. \\ São José dos Campos, SP, Brazil \\ fernando@geopx.com.br
}

\author{
Cláudia Almeida, Leila Fonseca, Lívia Tomás, \\ Paulo Gurgel Albuquerque, Cléber Oliveira \\ National Institute for Space Research - INPE \\ São José dos Campos, SP, Brazil \\ \{almeida, livia, gurgel, cleber\}@dsr.inpe.br; \\ leila@dpi.inpe.br
}

\begin{abstract}
The assessment of elevation accuracy of digital elevation models (DEM), which comprise digital surface models (DSM) and digital terrain models (DTM), has become a recurrent theme in the scientific literature in the latest decades. Accuracy tests are specifically based on a $10 \%$ level of statistical significance and they comprise both trend and precision analyses. Both tests were applied to data obtained from an air survey accomplished with the ALTM 2025 laser scanning sensor for a central sector of Uberlandia city, Brazil. The statistical tests for the DSM and DTM demonstrated that the mean elevation error respectively lay around $0,41 \mathrm{~m}$ and $0,48 \mathrm{~m}$, and the RMSE about $0,48 \mathrm{~m}$ and $0,47 \mathrm{~m}$. In both cases, the presence of trend in the $H$ direction was observed, revealing systematic influences in this component. This trend was further removed by means of algebraic manipulations. The precision analysis revealed that the DSM and DTM were compatible with a 1:5,000 scale and were up to the standard of the highest cartographic accuracy category (class A - PEC).
\end{abstract}

Keywords-LiDAR; cartographic quality control; GPS control points; trend analysis; accuracy analysis

\section{INTRODUCTION}

Cartography has as its premise the reliable and appropriate representation of spatial data either by analogical or digital means. The usage purposes of cartographic products are manifold and they demand distinct levels of precision and reliability [1]. As in [2], the reasons underlying the need of applying quality control processes to cartographic products are the lack of suitable norms to regulate the entire process of maps production and the rapid development of the digital cartography, resulting from the ever increasing demand for cartographic update and mapping, which tends to accelerate and customize the cartographic production processes to the detriment of their own quality.

The assessment of elevation accuracy of digital elevation models (DEM), which comprise digital surface models (DSM) and digital terrain models (DTM), has become a recurrent theme in the scientific literature in the latest decades. In Brazil, the legislation that regulates the quality of cartographic products are given by the Decree Law n. 89.817 [3], which establishes the guidelines of the National Cartography Technical Standards. According to this Decree, the elevation accuracy standards are ruled by the Cartographic Accuracy Standard - CAS (Padrão de Exatidão Cartográfica - PEC) and determined as a function of equidistance between contour lines. Such Decree states that $90 \%$ of scattered elevation points obtained by the interpolation of contour lines, when tested on the terrain, must not present an error superior to the one established by $P E C$.

Accuracy tests are specifically based on a $10 \%$ level of statistical significance and they comprise both trend and precision analyses. Both tests were applied to data obtained from an air survey accomplished with the ALTM 2025 laser scanning sensor for a central sector of Uberlandia city, located in the southeastern state of Minas Gerais, Brazil. A thorough description of the methods employed for such statistical tests as well as a critical discussion on the results obtained are presented in the following sections.

\section{STUDY AREA}

The selected study area concerns a central sector of Uberlandia city, located in the southeastern State of Minas Gerais, Brazil (Fig. 1a and 1b). The city is located $550 \mathrm{~km}$ away from Belo Horizonte, the state capital, and has the following coordinates $18^{\circ} 55^{\prime} \quad 07^{\prime \prime} \mathrm{S}$ and $48^{\circ} 16^{\prime} 38^{\prime \prime} \mathrm{W}$. Uberlandia city presents a cluster of high-rise buildings in its central neighborhoods, within which the study area is contained (Fig. 1c and 1d). The municipality had a population of 608,369 inhabitants in 2007.

The city itself, which is the municipality seat, is located on a mildly undulated terrain, with a mean altitude of $1,000 \mathrm{~m}$ above sea level and it presents a hot and tropical climate, with a mean annual rainfall of $1,500 \mathrm{~mm}$ and an average temperature of $22{ }^{\circ} \mathrm{C}$. The occupation patterns of the central neighborhoods in Uberlandia are very diverse, comprising green areas, oneand two-storey buildings as well as clusters of high-rise residential and business buildings. 


\section{Second International Workshop on Earth Observation and Remote Sensing Applications}

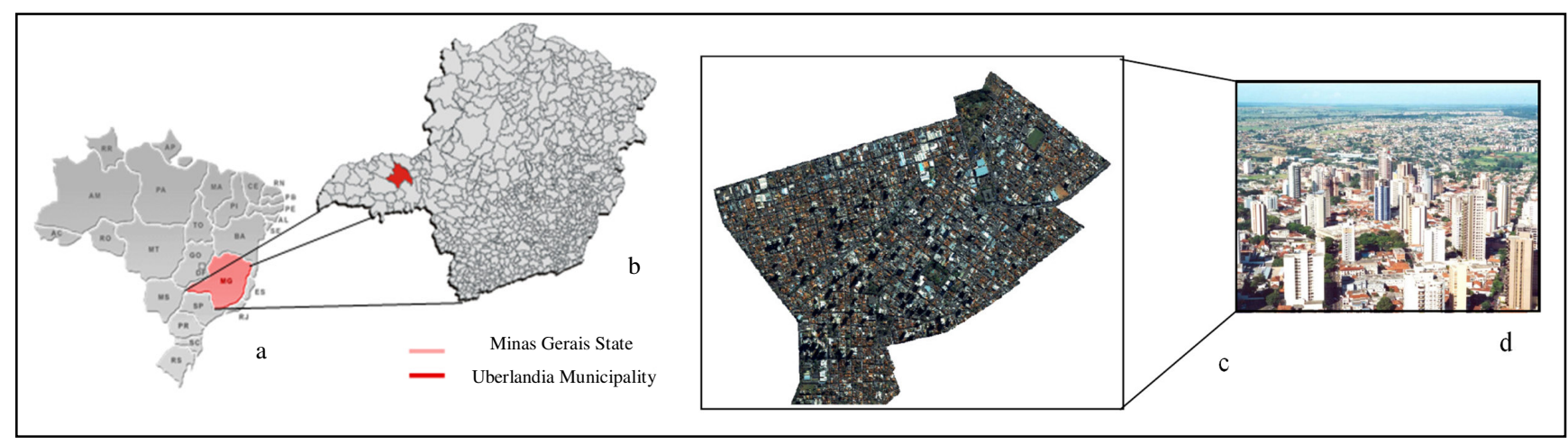

Figure 1. Study area: a. Brazil. b. Minas Gerais State and Uberlandia Municipality (in red). c. Study area (central sector of Uberlandia city, which is the municipality seat) in true color composition of IKONOS II images (1B_2G_3R). d. Aerial view of study area.

\section{LASER SCANNING DATA PROCESSING}

The acquired LiDAR data were pre-processed and delivered in ASCII format, containing the information of $X, Y$, and $Z$ coordinates as well as the intensity of the DSM and DTM. A filtering process was applied to the DSM, so as to obtain the DTM, and the module named TerraScan, available at the software Terra Solid, was employed for this end.

TerraScan collects the irregularly spaced $3 \mathrm{D}$ points cloud and by means of its terrain classifier, known as Axelsson's progressive TIN densification algorithm [4-5], it extracts points directly located on the terrain surface by constructing an iterative triangular irregular network (TIN). This algorithm initiates by selecting the parameter "building maximum size". If , for instance, this parameter is $60 \mathrm{~m}$, the software assumes that any area within $60 \times 60 \mathrm{~m}$ will have at least one point on the terrain and that the lowest point belongs to the terrain. In this work, this parameter was set to $85 \mathrm{~m}$.

Axelsson's algorithm initially builds a TIN considering the points with the lowest elevation. The triangles faces of the initial TIN are mostly situated below the terrain, and only their vertices touch the terrain. The algorithm then starts moving the TIN upwards through the iterative addition of new points belonging to the cloud to the network. Each newly added point makes the TIN get increasingly closer to the terrain.

The iteration parameters determine how close a point should be to a triangle face in order to be acknowledged as a point belonging to the terrain and be added to the TIN. The iteration angle is one of such parameters and it is defined as the maximum angle between a given point, its projection on the closest triangle face and the vertex of the closest triangle. The iteration distance parameter, on its turn, assures that there be no abrupt jump to the next iteration in case of big triangles. This is what enables that small buildings be included in the model. The smaller the iteration angle, the less sensitive the algorithm will be for detecting changes in the points cloud (small ondulations in the terrain or points located on vegetation of reduced height). According to the software producer, TerraSolid [6], it is recommendable to use a small angle (close to $4^{\circ}$ ) in flat areas and a bigger angle (approximately $10^{\circ}$ ) in steep areas.
It is possible to correct errors where the automatic classification (filtering process) did not present good results through the command "add point to the terrain". Upon basis of this classification result, two files in the TXT format were generated: one containing the DSM and another one the DTM. These TXT files were imported in ArcGIS 9.3 for the generation of surfaces, according to [7], in which a TIN initially created by means of the Delaunay triangulation is converted into a regular grid. This conversion procedure yielded the DSM and DTM files actually employed in this work.

\section{Methods FOR EleVATION ACCURACY ASSESSMENT}

\section{A. Cartographic Accuracy Standard}

As already mentioned in the Introduction, the elevation accuracy standards in Brazil are ruled by the Cartographic Accuracy Standard - CAS (Padrão de Exatidão Cartográfica $P E C)$ and determined as a function of equidistance between contour lines. As exposed in [3], 90\% of scattered elevation points obtained by the interpolation of contour lines, when tested on the terrain, must not present an error superior to the one established by $P E C$.

$P E C$ is a statistical indicator of dispersion related to a $90 \%$ of probability, which defines the accuracy of cartographic products. This $90 \%$ probability corresponds to 1.6449 times the standard error (SE), and isolated errors in a cartographic product must not exceed $60.8 \%$ of PEC. The standard error (also known as the standard deviation or the root mean square error - RMSE) is given by:

$$
R M S E=\sqrt{\frac{\sum\left(Z_{i}-Z_{t}\right)^{2}}{n}},
$$

where $Z_{i}=$ elevation of a point in the DEM or in a image, for instance; $\mathrm{Z}_{\mathrm{t}}=$ elevation of point collected in the field; and $n=$ number of evaluated points.

According to [3], the cartographic products are ranked as a function of their accuracy as belonging to the categories A, B, and $\mathrm{C}$, as shown in Table 1. 


\section{Second International Workshop on Earth Observation and Remote Sensing Applications}

TABLE I. $\quad$ CARTOGRAPHIC ACCURACY STANDARD - PEC

\begin{tabular}{|l|c|c|}
\hline $\begin{array}{c}\text { Cartographic } \\
\text { Product }\end{array}$ & $\begin{array}{c}\text { Elevation Accuracy } \\
\text { Standard - PEC }\end{array}$ & Standard Error \\
\hline Class A & $1 / 2 *$ Equidistance & $1 / 3 *$ Equidistance \\
\hline Class B & $3 / 5 *$ Equidistance & $2 / 5 *$ Equidistance \\
\hline Class C & $3 / 4 *$ Equidistance & $1 / 2 *$ Equidistance \\
\hline
\end{tabular}

In order to fulfill these requirements, it is necessary to conduct a statistical evaluation taking into account the discrepancies between the coordinates of points belonging to the cartographic product under analysis and the coordinates of homologous points obtained by field survey, provided that these two sets of data lie within the same cartographic projection system and datum.

As previously stated, accuracy tests are specifically based on a $10 \%$ level of statistical significance and they comprise both trend and precision analyses.

\section{B. $\quad$ Trend Analysis}

According to [8], the trend analysis is based on a statistical analysis of discrepancies between the observed coordinates in the cartographic product and the reference coordinates, calculated for each sample point $i$ as:

$$
\Delta X_{i}=X_{i}-X_{i}^{T},
$$

where $X_{i}$ are the calculated values, and $X_{i}^{T}$ are the reference values.

The mean and the standard deviation of the sampling differences are calculated as:

$$
\overline{\Delta X}=\frac{1}{n} \sum_{i=1}^{n} \Delta X_{i}
$$

and

$$
S_{\Delta X}^{2}=\frac{1}{n-1} \sum_{i=1}^{n}\left(\Delta X_{i}-\overline{\Delta X}\right)^{2}
$$

In the trend tests, the following hypotheses are evaluated:

$$
\begin{aligned}
& H_{0}: \overline{\Delta X}=0, \text { against } \\
& H_{1}: \overline{\Delta X} \neq 0 .
\end{aligned}
$$

In this test, the sample $t$ statistic ( $t_{\text {sample }}$ ) must be calculated in order to check if its value lies within the interval for accepting or refusing the null hypothesis.

The value of the sample $t$ statistic is calculated as:

$$
t_{X}=\frac{\overline{\Delta X}}{S_{\Delta X}} \sqrt{n},
$$

and the confidence interval as:

$$
\left|t_{X}\right|<t_{(n-1 ; \alpha / 2)} \text {. }
$$

If the sample $t$ statistic lies out of the confidence interval, the null hypothesis is rejected, i.e. the cartographic product must not be regarded as free of meaningful trends in the evaluated coordinate for the given significance level [8]. The presence of trends in any direction indicates the occurrence of a problem (which may have many causes), but once the cause is identified, its effect can be minimized by the subtraction of its value in each coordinated of the cartographic product [8].

\section{Precision Analysis}

The precision analysis, on its turn, concerns the comparison of the standard deviation related to the discrepancies with the expected standard deviation for the desired class by means of a hypothesis test. This test is formulated as follows:

$$
\begin{aligned}
& H_{0}: S_{X}^{2}=\sigma_{X}^{2}, \text { against } \\
& H_{1}: S_{X}^{2}>\sigma_{X}^{2},
\end{aligned}
$$

where $\sigma_{X}$ is the expected standard deviation for the class of interest.

Once the variance is calculated, the expected standard deviation can be computed:

$$
\chi_{X}^{2}=(n-1) \frac{S_{\Delta X}^{2}}{\sigma_{X}^{2}},
$$

and we then verify if its value lies within the interval of acceptance, as follows:

$$
\chi_{X}^{2} \leq \chi_{(n-1 ; \alpha)}^{2} .
$$

If the above expression is not fulfilled, the null hypothesis $H_{0}$ is rejected, and the cartographic product is regarded as not meeting the pre-established precision.

When the analysis is conducted not for the components, but for their resultants, the equation to be used is more simple:

$$
S_{\Delta X}=S E \text {. }
$$

\section{Sampling in Cartographic Accuracy Assessment}

A sound accuracy assessment procedure depends on the number of points to be used. In this way, it is not possible to have a limited number of points, in which case one cannot assure the assessment is reliable, nor an excessive number of points, for which the analysis is reliable, but the costs are unfeasible [1].

For [9], the accuracy of a map in a small scale $(1: 20,000$ and inferior) must be assessed with a minimum number of 20 points well defined both in the map and on the terrain (homologous points), the latter ones being related, for instance, to streets intersections or boundaries of real state properties. 


\section{Second International Workshop on Earth Observation and Remote Sensing Applications}

The size of a sample refers to the amount of unities or individuals within a given universe which are actually considered for analysis. It is known that samples selection must occurr on a random basis, so as to avoid any bias in the sampling procedure. By determining an appropriate sample size, it is possible to reduce costs and time in the analysis while increasing at the same time the data reliability [1].

\section{E. $\quad$ DSM and DTM Elevation Accuracy Assessment}

According to USGS guidelines [10], the minimum amount of checking points for calculating the root mean square error (RMSE) of a DEM is 28 , out of which 20 must be located in the central part of it and 8 in its borders. Out of the 55 GPS points collected in static mode in the field, 42 of them were actually used for assessing the DSM and DTM accuracy (Fig. 2 and 3). They were located in easily identifiable places, well distributed over the scene and lying within the study area boundaries.

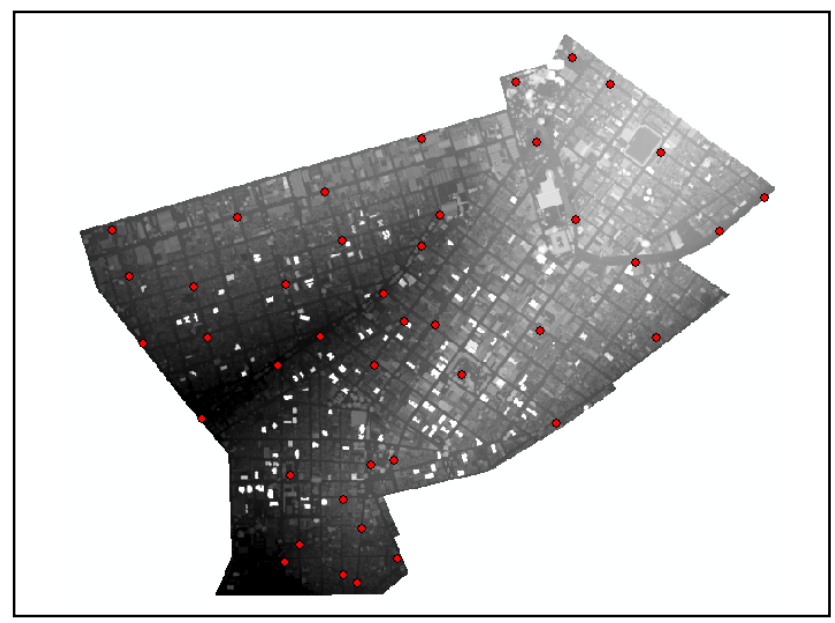

Figure 2. Points used for the DSM accuracy assessment.

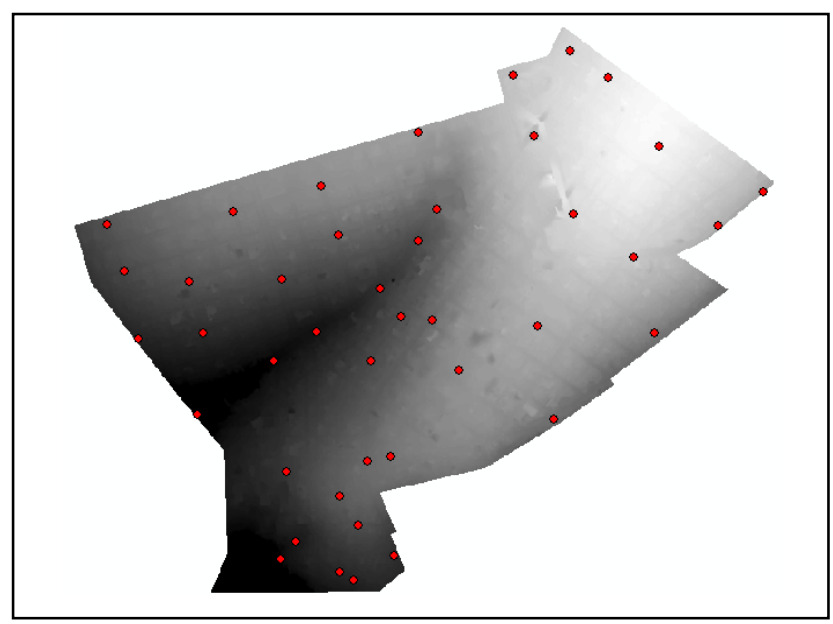

Figure 3. Points used for the DTM accuracy assessment.

\section{RESULTS AND DISCUSSION}

The results obtained were derived from the application of the method proposed in [8] to the DSM and DTM and are presented next.

The statistical tests for the DSM demonstrated that the mean elevation error respectively lay around $0.41 \mathrm{~m}$, the standard error about $0.25 \mathrm{~m}$, and the RMSE approximately 0.48 $\mathrm{m}$, which was considered to be meaningful. The results of such tests are presented in Table 2.

TABLE II. RESULTS OF THE DSM TREND ANALYSIS FOR THE H COORDINATE

\begin{tabular}{|c|c|c|}
\hline \multicolumn{2}{|l|}{$n$} & 42 points \\
\hline \multicolumn{2}{|l|}{$\bar{X}_{H}$} & $0.4076 \mathrm{~m}$ \\
\hline \multicolumn{2}{|l|}{$S_{H}$} & $0.2463 \mathrm{~m}$ \\
\hline \multicolumn{2}{|l|}{$S E_{1: 5,000}$} & $0.6667 \mathrm{~m}$ \\
\hline \multicolumn{2}{|l|}{$\sigma_{x}$} & 0.4714 \\
\hline \multicolumn{2}{|l|}{$t_{41 ; 5 \%}$} & 1.6829 \\
\hline \multicolumn{2}{|l|}{$t_{H}$} & 10.7259 \\
\hline \multicolumn{2}{|l|}{ Analysis } & $\left|t_{H}\right|>t_{\text {sample }}$ \\
\hline Component & $\mathbf{H}$ & presents trend \\
\hline
\end{tabular}

By comparing the sample $t$ statistic $\left(t_{\text {sample }}\right)$ with its theoretical value, one can notice the presence of trend in the $\mathrm{H}$ direction. Considering that there exist systematic influences in this component, it is possible to take the mean value of the confidence interval with the opposite $\operatorname{sign}\left(\bar{X}_{H}=-0,4076\right)$ and introduce it in the $\mathrm{H}$ coordinate, in an attempt to reduce discrepancies. The results of the precision analysis of the DSM are presented in Table 3.

TABLE III. RESULTS OF THE DSM PRECISION ANALYSIS FOR THE H COORDINATE

\begin{tabular}{|c|c|}
\hline$n$ & 42 points \\
\hline$\chi_{41 ; 10 \%}^{2}$ & 52.9485 \\
\hline$S_{H}$ & $0.2463 \mathrm{~m}$ \\
\hline$\sigma_{x}$ & $0.4714 \mathrm{~m}$ \\
\hline$\chi_{H\left(\text { Class_A }_{-}\right)}^{2}$ & 11.1873 \\
\hline Analysis & $\chi_{\left(\text {Class_A }_{-}\right)}^{2}<\chi_{41 ; 10 \%}^{2}$ \\
\hline Scale to be used & $1: 5,000$ \\
\hline
\end{tabular}

Even though the DSM lacks accuracy for a 1:5,000 scale, it presents precision for such scale. Nevertheless, its use should observe some reservations in face of the observed trend.

The statistical tests for the DTM demonstrated that the mean elevation error reached around $0.48 \mathrm{~m}$, the standard error about $0.25 \mathrm{~m}$, and the RMSE approximately $0.47 \mathrm{~m}$, which was also 


\section{Second International Workshop on Earth Observation and Remote Sensing Applications}

regarded as expressive. The results of such tests are presented in Table 4.

TABLE IV. RESULTS OF THE DTM TREND ANALYSIS FOR THE H COORDINATE

\begin{tabular}{|c|c|c|}
\hline \multicolumn{2}{|l|}{$n$} & 42 points \\
\hline \multicolumn{2}{|l|}{$\bar{X}_{H}$} & $0.4844 \mathrm{~m}$ \\
\hline \multicolumn{2}{|l|}{$S_{H}$} & $0.2506 \mathrm{~m}$ \\
\hline \multicolumn{2}{|l|}{$S E_{1: 5,000}$} & $0.6667 \mathrm{~m}$ \\
\hline \multicolumn{2}{|l|}{$\sigma_{x}$} & 0.4714 \\
\hline \multicolumn{2}{|l|}{$t_{41 ; 5 \%}$} & 1.6829 \\
\hline \multicolumn{2}{|l|}{$t_{H}$} & 12.53 \\
\hline \multicolumn{2}{|l|}{ Analysis } & $\left|t_{H}\right|>t_{\text {sample }}$ \\
\hline Component & $\mathbf{H}$ & presents trend \\
\hline
\end{tabular}

Likewise the DSM, the DTM presented trend in the $\mathrm{H}$ direction as well, revealing systematic influences in this component. This trend was removed by means of algebraic manipulations in the same way it was done for the DSM. The results of the precision analysis of the DTM are presented in Table 5.

TABLE V. RESULTS OF THE DTM PRECISION ANALYSIS FOR THE H COORDINATE

\begin{tabular}{|c|c|}
\hline$n$ & 42 points \\
\hline$\chi_{41 ; 10 \%}^{2}$ & 52.9485 \\
\hline$S_{H}$ & $0.2506 \mathrm{~m}$ \\
\hline$\sigma_{x}$ & $0.4714 \mathrm{~m}$ \\
\hline$\chi_{H\left(\text { Class_A }_{2}\right.}^{2}$ & 11.5820 \\
\hline Analysis & $\chi_{\left(\text {Class_A }_{-}<\right.}^{2}<\chi_{41 ; 10 \%}^{2}$ \\
\hline Scale to be used & $1: 5,000$ \\
\hline
\end{tabular}

The DTM, in a similar way to the DSM, lacks accuracy for a 1:5,000 scale, although it presents precision for such scale. The precision analysis revealed that both the DSM and DTM were compatible with a 1:5,000 scale and were up to the standard of the highest $P E C$ category (class A).

\section{CONCLUSIONS}

It is worth mentioning that although both the DSM and DTM achieved the highest accuracy standard (class A) for a 1:5,000 scale, their use should be carefully evaluated for certain applications in view of the trend observed in the $\mathrm{H}$ direction.

\section{ACKNOWLEDGMENT}

The authors gratefully acknowledge the financial support granted to this research by the Brazilian National Institute for Space Research (INPE) and the Brazilian Coordination for the Upgrade of Graduate Personnel (CAPES).

\section{REFERENCES}

[1] J. B. Nogueira Jr., "Quality control of cartographic products: a methodological proposal," Master's Thesis, Department of Cartography - Faculty of Science and Technology of the State University of São Paulo, Presidente Prudente: UNESP, 2003.

[2] E. M. Leal, and Q. Dalmolin, "Analysis of the positional accuracy of a cartographic database," Proceedings of the 5th Congress on Geoprocessing of Latin America - GISBRASIL, Salvador, BA, Brazil, 1999.

[3] Brazil, "Decree n. 89.817, June 20, 1984," Deals with the instructions on the regulating technical norms of the national cartography, Brasília: Official Diary of the Federal Republic of Brazil, June 22, 1984.

[4] P. Axelsson, "Processing of laser scanner data - algorithms and applications," ISPRS J. Photogramm., Netherlands, vol. 54, pp. 138147, July 1999.

[5] P. Axelsson, "DEM generation from laser scanning data using adaptive TIN models," ISPRS International Archives of Photogrammetry and Remote Sensing, vol. 33, part B4/1, pp. 110-117, 2000.

[6] TerraSolid, “TerraScan user's guide," 2010, Available at http://www.terrasolid.fi.

[7] G. Patenaude, R. A. Hill, R. Milne, D. L. A. Gaveau, B. B. J. Briggs, and T. P. Dawson, "Quantifying forest above ground carbon content using LiDAR remote sensing," Remote Sens. Environ., vol. 93, pp. 368-380, 2004.

[8] M. Galo, P. O. Camargo, "Use of GPS for the quality control of cartographic products," Proceedings of the Brazilian Congress on Multipurpose Technical Cadastre - Florianópolis, SC, Brazil, Florianópolis: Federal University of Santa Catarina, 1994.

[9] D. C. Merchant, "Spatial Accuracy Standard For Large Scale Line Maps," Proceedings of the American Congress on Surveying and Mapping, vol. 1, pp. 222-231, 1982.

[10] United States Geological Survey (USGS), Department of the Interior, U.S.A., National Mapping Division, "Standards or digital elevation models," Reston, VA: USGS, 1998. 